\title{
Sección: Política Internacional
}

\section{Introducción}

Lía Rodriguez de la Vega ${ }^{1}$

UP - CICS

El proceso globalizador no solamente ha profundizado los espacios de contacto entre los sujetos y los distintos actores del sistema internacional -con gran impacto económico y de movilidad de las personas(Beck, 1988) sino que por ello mismo, entre otros, se continúa fortaleciendo la discusión y abordajes sobre los derechos humanos y, más allá de atender la consideración de derechos como los relacionados a la identidad cultural (Kymlicka, 1996) y los derechos humanos de cuarta generación, se requiere revisitar algunos otros, tales como los que hacen a la situación de la mujeres ( $y$ de otras identidades de género) en el mundo.

Con respecto a lo primero, la dinámica geopolítica mundial trae con enorme impulso proyectos de más y mejor comunicación, al tiempo que extensión económica asociada a ello. En ese marco, distintos estados proponen diversas iniciativas, tal el caso del Cinturón Económico de la Ruta de la Seda y la Ruta Marítima de la Seda del Siglo XXI, propuesta por China. La misma enfatiza la mejora de las comunicaciones y en ese marco, la de los transportes, haciendo de ese sector un ámbito privilegiado de inversiones y activación de dinámicas de poder y proyección internacional.

La Ruta de la Seda, como sabemos, fue la vía mercantil que vinculó desde hace miles de años el Lejano Oriente con diversos lugares del África, Asia Central y Europa. A través de ella se comercializaron diversos productos, entre los que pueden mencionarse la porcelana, el jade, las especias e incluso está relacionada también a la difusión del Budismo. La consolidación del Imperio Otomano y la caída de Constantinopla en 1453, implicó la búsqueda y desarrollo de nuevas rutas.

\footnotetext{
${ }^{1}$ Dra. en Relaciones Internacionales (USAL); Estancia post doctoral en la Universidad Federal de Rio Grande do Sul (UFRGS), Porto Alegre, Brasil. Docente e investigadora de la Facultad de Ciencias Sociales e investigadora del CICS (UP), Responsable Del Área de Asia y África de UNICOM, Facultad de Ciencias Sociales (UNLZ) y Coordinadora del Grupo de Trabajo de India y Asia del Sur, Comité de Asuntos Asiáticos, Consejo Argentino para las Relaciones Internacionales. Correo electrónico: liadelavega@yahoo.com
} 
La dimensión terrestre de esta iniciativa se propone conectar a China con Asia Central, la Europa del Báltico y Rusia, al mismo tiempo que generar vínculos entre China y el Golfo Pérsico, Mediterráneo, Sur de Asia, Sudeste asiático y también el Océano Índico. La dimensión marítima, por su parte, tiene por objetivo generar nuevas conexiones entre la costa china con Europa, a través del Mar de China y el Océano Índico, en una sola ruta e integrar la zona meridional del Mar de China con el Pacífico Sur.

Comprende distintas cuestiones que consideran desde la construcción de instalaciones para la facilitación del comercio, infraestructura en transporte y energía renovable, promoción de la cooperación en la expansión de inversiones y comercio, desarrollo de las comunicaciones, entre otros muchos sectores (National Development and Reform Commission, Ministry of Foreign Affairs, and Ministry of Commerce of the People's Republic of China, 2015).

Con respecto a lo segundo, los derechos humanos, especialmente de las mujeres, cabe decir que la adopción de la declaración de Viena y el Programa de Acción (Viena+5), por parte de los Estados que participaron en la Conferencia Mundial de las Naciones Unidas sobre los Derechos Humanos (Viena, 1993), es considerado un momento clave en el movimiento de derechos de la mujer, en tanto allí se abrió el camino para una integración creciente de los derechos de la mujer y la perspectiva de género a la normativa y práctica de los derechos humanos (The Geneva Academy of International Humanitarian Law and Human Rights, 2014).

En la actualidad, debemos aún observar la universalidad de los derechos en la práctica, en tanto las mujeres y niñas continúan siendo víctimas de distintas formas de discriminación, que no solamente minan sus posibilidades de desarrollo personal sino, por eso mismo, las de las sociedades de las que forman parte.

La discriminación se manifiesta de distintas maneras, que van desde la diferencia social, el prejuicio, su no acceso a la educación o al ámbito laboral fuera de la casa, su remuneración diferenciada con respecto a los hombres, su no acceso al derecho a voto en determinados lugares, el avance desmesurado de la pobreza entre las mujeres, etc., las vejaciones -como el caso de las violaciones correctivas de lesbianas, las violaciones que buscan amedrentar su participación política, la violación sistemática de niñas y mujeres como arma de guerra, las lapidaciones públicas de mujeres consideradas adúlteras- hasta incluso la muerte (desaparición de hijas mujeres en los primeros 5 años de vida o antes de nacer, femicidios, etc.). 
Una revisión global devuelve la negación de sus derechos en diversos ámbitos en escala significativa. Así, se estima que alrededor de 140 millones de mujeres y niñas en el mundo viven con las consecuencias de la mutilación genital femenina, miles mueren por embarazo o complicaciones relacionadas con el parto, trayendo a cuestión sus derechos reproductivos y el acceso a servicios médicos de calidad; miles atraviesan cada año los denominados "homicidios de honor" y otras tantas niñas son obligadas a contraer matrimonios precoces que pueden terminar en su muerte; miles de mujeres son muertas o heridas cada año en las muertes asociadas a la temática de la dote, etc. (The Geneva Academy of International Humanitarian Law and Human Rights, 2014).

Estos temas no solamente son actuales en tanto indican con mucha evidencia niveles y alcances del desarrollo y todo lo que ello implica sino que, en este caso, nos permiten revisar aspectos de los dos países más poblados del mundo y sus dinámicas internas e internacionales, que tienen resonancia global y dan cuenta de las distintas circunstancias relativas a las articulaciones entre lo local y lo global. Los autores que participan en la sección en este número, trayendo estos temas son Sabrina Olivera, miembro del Grupo de Trabajo sobre India y Asia del Sur, del Comité de Asuntos Asiáticos del Consejo Argentino para las Relaciones Internacionales, y Ezequiel Ramoneda, Coordinador del Centro de Estudios del Sudeste Asiático, del Instituto de Relaciones Internacionales de la Universidad Nacional de La Plata.

\section{Referencias Bibliográficas}

BECK, U. (1998). ¿Qué es la globalización? Falacias del globalismo, respuestas a la globalización. Buenos Aires: Paidós.

KYMLICKA, W. (1996). Ciudadanía Multicultural. Barcelona: Paidós.

NATIONAL DEVELOPMENT AND REFORM COMMISSION, Ministry of Foreign Affairs, and Ministry of Commerce of the People's Republic of China (2015). "Vision and Actions on Jointly Building Silk Road Economic Belt and 21st-Century Maritime Silk Road". National Development and Reform Commission, People's Republic of China. Recuperado de:

http://en.ndrc.gov.cn/newsrelease/201503/t20150330 669367.html 
THE GENEVA ACADEMY OF INTERNATIONAL HUMANITARIAN LAW AND HUMAN RIGHTS (2014). The Situation of Women's Rights 20 Years after the Vienna World Conference on Human Rights. ACADEMY INBRIEF No. 4. Recuperado de:

http://www.geneva-academy.ch/docs/publications/ga inbrief4 Women's\%20Rights\%20.pdf 